\title{
Chlorophyll a fluorescence of sweet potato plants cultivated in vitro and during ex vitro acclimatization
}

\author{
Francine F. Cassana ${ }^{1 *}$, Antelmo R. Falqueto ${ }^{2}$, Eugenia J. B. Braga ${ }^{1}$, \\ Jose A. Peters ${ }^{1}$ and Marcos A. Bacarin ${ }^{1}$ \\ ${ }^{1}$ Universidade Federal de Pelotas, Departamento de Botânica, Instituto de Biologia, Pelotas/RS - 96010-900, Brazil \\ ${ }^{2}$ Universidade Federal do Espírito Santo, Departamento de Ciências Agrárias e Biológicas, Centro Universitário \\ Norte do Espírito Santo, São Mateus/ES - 29.932-540, Brazil
}

*Corresponding author: fax: (+55) 53-3275-7169, e-mail: francinecassana@yahoo.com.br

Received: 11 April 2010; Accepted: 25 October 2010

\begin{abstract}
Sweet potato (Ipomoea batatas L.) plants were cultivated in vitro in Murashige and Skoog (MS) medium with 20 and $40 \mathrm{~g} \mathrm{~L}^{-1}$ of sucrose under two different photon flux densities (21 and $60 \mu \mathrm{mol} \mathrm{m}^{-2} \mathrm{~s}^{-1}$ ). Leaves developed in vitro mostly showed high variable to maximum fluorescence ratio $\left(\mathrm{F}_{\mathrm{V}} / \mathrm{F}_{\mathrm{M}}\right)$, indicating good development of photosynthetic apparatus. This ratio decreased during leaf aging, especially in the plants cultivated in vitro on medium with higher sucrose concentration and higher photon flux. Leaves developed ex vitro showed high $\mathrm{F}_{\mathrm{V}} / \mathrm{F}_{\mathrm{M}}$ ratio during whole experiment. The effective photochemical efficiency $\left(\mathrm{F}_{\mathrm{v}}{ }^{\prime} / \mathrm{F}_{\mathrm{M}}{ }^{\prime}\right)$ was maximum at 15 th day after emergence of leaves. Photosynthetic potential rate was higher in leaves developed in vitro than in leaves originated ex vitro.
\end{abstract}

Key words: culture medium, photon flux density, photosystem, sucrose.

Abbreviations: $B A-6$ - benzylaminopurine; $F_{V} / F_{M}$ - maximum photochemical efficiency; $F_{v}{ }^{\prime} / F_{M}{ }^{\prime}$ - effective photochemical efficiency; MS - Murashige and Skoog; PPF - photosynthetic photon flux.

\section{INTRODUCTION}

During in vitro culture, plantlets usually grow under nutritional and physical conditions which characterize a mixotrophic and/or heterotrophic growth, depending on external sugar source (Le et al., 2001). In general, leaves developed during in vitro culture show reduced capacity to synthesize organic compounds. Also, the photosynthetic apparatus of plants growing in vitro is not completely active (Fuentes et al., 2005). According Amâncio et al., (1999), variations of the photosynthetic photon flux (PPF) during in vitro culture should influence both leaf and chloroplast development. In addition, in vitro conditions should determine alterations of morphologic, anatomic and physiological characteristics of the plantlets, doing the ex vitro establishment of the plantlets a hardly mission (Semorádová et al., 2002). When plantlets cultivated in vitro are transferred to ex vitro conditions, the development of new leaves assume primordial importance to development and establishment of plantlets (Viña et al., 1999).

The chlorophyll a fluorescence is an efficient tool used in photosynthetic investigations as fast and non-destructive method suitable to indicate the photosynthetic response of plants to stress (Saquet and Streift, 2002; Barbagallo et al., 2003), providing an indication of photosynthetic performance of plants. Moreover, preliminary studies showed that the 
sucrose concentration in the culture media and photon flux density, at which plants are subjected in vitro, alter the $\mathrm{F}_{\mathrm{v}} /$ $F_{M}$ leaves ratio (Cassana et al., 2008). This study aimed to evaluate the photosynthetic capacity of sweet potato plantlets cultivated in vitro under different sucrose concentrations and photosynthetic photon flux using the chlorophyll a fluorescence and oxygen evolution rate measurements.

\section{MATERIAL AND METHODS}

Nodal segments $(1 \mathrm{~cm}$ length) from sweet potato (Ipomoea batatas L. Cv. ILS19) meristem cultures were inoculated in MS (Murashige and Skoog, 1962) basal medium supplemented with $0.5 \mathrm{mg} \mathrm{L}^{-1}$ of 6 - benzylaminopurine (BA) and two sucrose concentrations (20 and $40 \mathrm{~g} \mathrm{~L}^{-1}$ ). In order to compare the photosynthetic capacity of plantlets in in vitro and ex vitro conditions, measurements also were performed after the acclimatization of plantlets in greenhouse conditions. Therefore, after inoculation, the plantlets were placed in plant growth chamber for 45 days, with 16 h photoperiod, $25 / 23 \pm 1{ }^{\circ} \mathrm{C}$ air temperature (during light and dark period, respectively) and 21 and $60 \mu \mathrm{mol} \mathrm{m} \mathrm{m}^{-2} \mathrm{~s}^{-1}$ PPF provided by fluorescent lamps.

The maximum and effective photochemical efficiency $\left(F_{\mathrm{V}} / \mathrm{F}_{\mathrm{M}}\right.$ and $\mathrm{F}_{\mathrm{v}}{ }^{\prime} / \mathrm{F}_{\mathrm{M}}{ }^{\prime}$, respectively) were measured using a portable fluorometer FMS 2 (Hansatech, UK). The first measurement was made at last day of in vitro culture (day zero). Afterwards, the plantlets were transplanted and acclimatized in greenhouse under $23-28^{\circ} \mathrm{C}$ air temperature and $80 \%$ relative humidity. In these (in vitro) leaves, the chlorophyll fluorescence determinations were repeated weekly until $29 \mathrm{~d}$. On the other hand, for new leaves emerged during the acclimatization (ex vitro), which appeared after 45 days in greenhouse, the assay was repeated weekly the same determinations until the $29^{\text {th }}$ day.

The photosynthetic potential rate $\left(\mu \mathrm{mol} \mathrm{O}_{2} \mathrm{~m}^{-2} \mathrm{~s}^{-1}\right)$ was estimated at day zero (in vitro leaves) and day one (ex vitro leaves) using the LeafLab 2 (Hansatech, UK). In this experiment, we had two growth conditions (combinations between sucrose and PPF) and leaves originated in vitro and ex vitro. Four replications per treatment were carried out. Each replication consisted of one vessel containing five plantlets and one plant, during in vitro and ex vitro culture, respectively.
All experiments were repeated three times and the statistical analysis was performed using the Statistical Analysis System for Microcomputers - SANEST (Zonta \& Machado, 1987) and the means compared by Tukey test $(p<$ 0.05).

\section{RESULTS AND DISCUSSION}

The maximum photochemical efficiency $\left(\mathrm{F}_{\mathrm{V}} / \mathrm{F}_{\mathrm{M}}\right)$ values were similar in the different treatments in leaves originated in vitro at day zero (Table 1), however, the lowest value of $\mathrm{F}_{\mathrm{V}} / \mathrm{F}_{\mathrm{M}}(0.773)$ was obtained by combination of $21 \mu \mathrm{mol} \mathrm{m}^{-2}$ $\mathrm{s}^{-1} \mathrm{PPF}$ and $20 \mathrm{~g} \mathrm{~L}^{-1}$ sucrose. Reduced values of this ratio have been related to damages on photosynthetic apparatus (Guo et al., 2006). During the acclimatization, the leaves originated in vitro showed different behaviors pattern along the time, depending on pretreatments to which the plantlets were submitted during the in vitro culture (Table 1). Values for the $F_{V} / F_{M}$ ratio reduced significantly in leaves of plantlets exposed to $60 \mu \mathrm{mol} \mathrm{m} \mathrm{m}^{-2} \mathrm{~s}^{-1} \mathrm{PPF}$ and $40 \mathrm{~g} \mathrm{~L}^{-1}$ sucrose during 15 days after the transfer of plantlets to greenhouse and after 29 days of acclimatization, the $F_{v} / F_{M}$ value reached 0.6 .

The effective photochemical efficiency in light adapted state $\left(F_{v}{ }^{\prime} / F_{M}{ }^{\prime}\right)$ can be used to estimate the photosystem II (PSII) operational efficiency (Baker and Rosenqvist, 2004). In the present study, $F_{v}{ }^{\prime} / F_{M}$ ' values obtained at day zero ranged from 0.707 to 0.762 , in the different pretreatments to which the plantlets were submitted, but such variation was not statistically significant (Table 1). However, the $F_{v}$ '/ $F_{M}$ ' ratio decreased with the acclimatization of plantlets, mainly in the leaves pretreated with $40 \mathrm{~g} \mathrm{~L}^{-1}$ sucrose, a decrease independent on the PPF. These results show that leaves of sweet potato plants cultured in vitro, although been persistent as well as been increased in size due mainly of cellular elongation (Fabbri et al., 1986), they could be classified such as competent species group, endowed with low photosynthetic capacity after acclimatization. This feature can be related to physiological stress caused by the environmental changes imposed to the plant during its transfer from in vitro to ex vitro conditions, especially in conditions of low sucrose concentration during in vitro culture. 
Table 1. Maximum photochemical efficiency $\left(F_{v} / F_{M}\right)$ and effective photochemical efficiency $\left(F_{v}{ }^{\prime} / F_{M}{ }^{\prime}\right)$ in sweet potato leaves originated in vitro. Different small letters indicate significant difference in the columns (means of sucrose; $p<0.05$ ). Different capital letters indicate significant differences in the rows (means of days; $\mathrm{p}<0.05$ ). Different Greek letters indicate significant differences in the columns (means of PPF; $p<0.05$ ). Day zero $(0)$ was considered when the leaf showed $10 \mathrm{~mm}$ of diameter and measured immediately before acclimatization.

\begin{tabular}{|c|c|c|c|c|c|c|c|}
\hline & \multirow{2}{*}{ 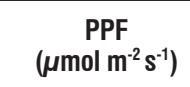 } & \multirow{2}{*}{$\begin{array}{c}\text { sucrose } \\
\left(\mathrm{g} \mathrm{L}^{-1}\right)\end{array}$} & \multicolumn{5}{|c|}{ days after acclimatization } \\
\hline & & & 0 & 8 & 15 & 22 & 29 \\
\hline \multirow{4}{*}{$\stackrel{\Sigma}{\longleftarrow}$} & 21 & 20 & $0.773 \mathrm{Aa} \beta$ & $0.830 \mathrm{Aa} \propto$ & $0.779 \mathrm{Aa} \propto$ & $0.782 \mathrm{Aa} \propto$ & $0.687 \mathrm{Ba} \propto$ \\
\hline & & 40 & $0.822 \mathrm{Aa} \propto$ & $0.786 \mathrm{ABa} \propto$ & $0.771 \mathrm{Aba} \propto$ & $0.746 \mathrm{BCa} \propto$ & $0.681 \mathrm{Ca} \propto$ \\
\hline & 60 & 20 & $0.827 \mathrm{Aa} \propto$ & $0.855 \mathrm{Aa} \propto$ & $0.807 \mathrm{ABa} \propto$ & $0.750 \mathrm{Ba} \propto$ & $0.668 \mathrm{Ca} \propto$ \\
\hline & & 40 & $0.823 \mathrm{Aa} \propto$ & $0.799 \mathrm{Ab} \propto$ & $0.666 \mathrm{Bb} \beta$ & $0.650 \mathrm{Bb} \beta$ & $0.603 \mathrm{Bb} \beta$ \\
\hline \multirow{2}{*}{\multicolumn{2}{|c|}{$F_{v}{ }^{\prime} / F_{M}{ }^{\prime}$}} & 20 & $0.707 \mathrm{Aa}$ & $0.593 \mathrm{Aa}$ & $0.425 \mathrm{Ba}$ & $0.289 \mathrm{Ca}$ & $0.207 \mathrm{Ca}$ \\
\hline & & 40 & $0.762 \mathrm{Aa}$ & $0.458 \mathrm{Bb}$ & $0.160 \mathrm{Cb}$ & $0.169 \mathrm{CB}_{\mathrm{B}}$ & $0.148 \mathrm{CA}_{\mathrm{A}}$ \\
\hline
\end{tabular}

The maximum photochemical efficiency $\left(\mathrm{F}_{\mathrm{V}} / \mathrm{F}_{\mathrm{M}}\right)$ of ex vitro leaves just varied with time (Table 2). At first day of evaluation, when the leaves were still very young, the maximum photochemical efficiency ranged from 0.808 to 0.837 with the lowest value obtained in leaves previously cultivated in 60 $\mu \mathrm{mol} \mathrm{m} \mathrm{m}^{-2} \mathrm{~s}^{-1}$ PPF and $40 \mathrm{~g} \mathrm{~L}^{-1}$ sucrose. However, during the growth and development of the leaves, it was observed an increased $F_{V} / F_{M}$ ratio in all treatments, and after 29 days the $F_{V} / F_{M}$ values were very high, varying from 0.829 to 0.852 . According Lichtenthaler et al., (2005), such a high values characterize non-stressed leaves, indicating that sweet potato plants were highly adapted to the greenhouse environmental condition.

The $F_{\mathrm{V}}{ }^{\prime} / \mathrm{F}_{\mathrm{M}}{ }^{\prime}$ of new leaves originated under greenhouse conditions (Table 2) was low at first day of evaluation, but it reached a maximum value $(0.817)$ at the $15^{\text {th }}$ day regardless the treatments applied in vitro culture. After this period, the effective photochemical efficiency decreased, but it remained higher than that values observed at first day of evaluation. The $\mathrm{F}_{\mathrm{v}}{ }^{\prime} / \mathrm{F}_{\mathrm{M}}{ }^{\prime}$ ration indicates the capacity of absorption of excitation energy by leaves, and it is usually lower in young leaves, increasing with age and decreasing thereafter as a consequence of leaf senescence.

Table 2. Maximum photochemical efficiency $\left(F_{\mathrm{V}} / F_{\mathrm{M}}\right)$ and effective photochemical efficiency $\left(\mathrm{F}_{\mathrm{V}}{ }^{\prime} / \mathrm{F}_{\mathrm{M}}{ }^{\prime}\right)$ in sweet potato leaves originated ex vitro (after acclimatization in greenhouse). Different small letters indicate significant differences in the columns (means of sucrose; $p<0.05$ ). Different capital letters indicate significant differences in the rows (means of leaf age; $p<0.05$ ). Different Greek letters indicate significant differences in the columns (means of PPF; $p<0.05$ ). Day one (1) was considered when the leaf showed $10 \mathrm{~mm}$ of diameter.

\begin{tabular}{|c|c|c|c|c|c|c|c|}
\hline & \multirow{2}{*}{$\begin{array}{c}\text { PPF } \\
\left(\mu \mathrm{mol} \mathrm{m}^{-2} \mathrm{~s}^{-1}\right)\end{array}$} & \multirow{2}{*}{$\begin{array}{l}\text { sucrose } \\
\left(\mathrm{g} \mathrm{L}^{-1}\right)\end{array}$} & \multicolumn{5}{|c|}{ Leaf age (days) } \\
\hline & & & 1 & 8 & 15 & 22 & 29 \\
\hline \multirow{5}{*}{$\underset{u^{z}}{z}$} & \multirow[t]{2}{*}{21} & 20 & 0.831 & 0.875 & 0.883 & 0.882 & 0.829 \\
\hline & & 40 & 0.834 & 0.872 & 0.885 & 0.875 & 0.844 \\
\hline & \multirow[t]{3}{*}{60} & 20 & 0.837 & 0.875 & 0.883 & 0.878 & 0.852 \\
\hline & & 40 & 0.808 & 0.871 & 0.881 & 0.883 & 0.846 \\
\hline & & Mean & $0.827 \mathrm{C}$ & $0.873 \mathrm{~A}$ & $0.883 \mathrm{~A}$ & $0.879 \mathrm{~A}$ & $0.842 \mathrm{~B}$ \\
\hline \multirow{4}{*}{$\sum_{i=}^{z}$} & \multirow[t]{2}{*}{21} & 20 & $\begin{array}{l}0.432 \\
\text { Сaळ }\end{array}$ & $\begin{array}{l}0.741 \\
\mathrm{ABa} \propto\end{array}$ & $\begin{array}{l}0.815 \\
\text { Aaœ }\end{array}$ & $\begin{array}{l}0.643 \\
\mathrm{Ba} \propto\end{array}$ & $\begin{array}{c}0.594 \\
\mathrm{Ba} \beta\end{array}$ \\
\hline & & 40 & $\begin{array}{l}0.440 \\
\mathrm{Ca} \propto\end{array}$ & $\begin{array}{l}0.723 \\
A B a \propto\end{array}$ & $\begin{array}{l}0.816 \\
\text { Aa } \propto\end{array}$ & $\begin{array}{l}0.614 \\
\mathrm{Ba} \propto\end{array}$ & $\begin{array}{l}0.679 \\
\mathrm{ABa} \propto\end{array}$ \\
\hline & \multirow[t]{2}{*}{60} & 20 & $\begin{array}{l}0.476 \\
\mathrm{Ca} \propto\end{array}$ & $\begin{array}{c}0.641 \\
\mathrm{Ba} \propto\end{array}$ & $\begin{array}{c}0.815 \\
\text { Aa } \propto\end{array}$ & $\begin{array}{l}0.584 \\
\mathrm{BCa} \propto\end{array}$ & $\begin{array}{l}0.706 \\
\mathrm{ABa} \propto\end{array}$ \\
\hline & & 40 & $\begin{array}{l}0.521 \\
\mathrm{Ba} \propto\end{array}$ & $\begin{array}{c}0.606 \\
\mathrm{Ba} \beta\end{array}$ & $\begin{array}{c}0.817 \\
\text { Aa } \propto\end{array}$ & $\begin{array}{c}0.611 \\
\mathrm{Ba} \propto\end{array}$ & $\begin{array}{c}0.490 \\
\mathrm{Bb} \beta\end{array}$ \\
\hline
\end{tabular}


When the photosynthetic potential rate measured in leaves at the end of in vitro cultivation was compared with the rate found in leaves originated after acclimatization (ex vitro), it was observed that only the condition factor in which the leaves were generated was significant (Table 3). Leaves generated by tissue culture, regardless the treatment to which the plants were subjected, presented average photosynthetic potential rate significantly higher $\left(29.60 \mu \mathrm{mol} \mathrm{O}_{2} \mathrm{~m}^{-2} \mathrm{~s}^{-1}\right)$ than the one shown by ex vitro originated leaves $\left(22.21 \mu \mathrm{mol} \mathrm{O}_{2} \mathrm{~m}^{-2} \mathrm{~s}^{-1}\right)$. Le et al., (2001) studied the effects of exogenous sucrose ( 0 and $3 \%$ ) on the oxygen evolution rate of tomato plants (Lycopersicon esculetum Mill.) cultured in vitro under low and high PPF (50 and $500 \mu \mathrm{mol} \mathrm{m}^{-2} \mathrm{~s}^{-1}$ ) and verified that the exogenous sucrose had a positive effect on oxygen evolution process (from 11.22 to $15.75 \mu \mathrm{mol} \mathrm{O}_{2} \mathrm{~m}^{-2} \mathrm{~s}^{-1}$, after 20 days of in vitro cultivation with low PPF and low carbon dioxide concentration).

Table 3. Oxygen evolution rate $\left(\mu \mathrm{mol} \mathrm{O}_{2} \mathrm{~m}^{-2} \mathrm{~s}^{-1}\right)$ of sweet potato plant in vitro originated leaves immediately before being transferred to acclimatization and of leaves originated during acclimatization (ex vitro). Different capital letters indicate significant differences in the rows and compare condition in which the leaves were generated $(p<0.05)$.

\begin{tabular}{cccc}
\hline \multirow{2}{*}{$\begin{array}{c}\text { Photon flux density } \\
\left(\boldsymbol{\mu} \text { mol m } \mathbf{~ s}^{-1}\right)\end{array}$} & Sucrose $\left(\mathbf{g ~ L}^{-1}\right)$ & \multicolumn{2}{c}{$\begin{array}{c}\text { Photosynthetic potential rate } \\
\left(\boldsymbol{\mu} \mathrm{mol}_{2} \mathbf{~ m}^{-2} \mathbf{s}^{-1}\right)\end{array}$} \\
\cline { 3 - 4 } & & In vitro & Ex vitro \\
\hline 21 & 20 & 27.08 & 21.65 \\
& 40 & 31.03 & 21.26 \\
\hline 60 & 20 & 30.46 & 22.18 \\
& 40 & 29.84 & 23.75 \\
\hline Mean & & $29.60 \mathrm{~A}$ & $22.21 \mathrm{~B}$ \\
\hline
\end{tabular}

The data from the present study taken together with those of the literature cited make it possible to conclude that: (1) the leaves growth in in vitro and ex vitro conditions showed similar maximum photochemical efficiency and (2) the conditions of in vitro culture can influence the chlorophyll fluorescence parameters.

\section{REFERENCES}

Baker NR, Rosenqvist (2004) Applications of chlorophyll fluorescence can improve crop production strategies: an examination of future possibilities. J. Exp. Bot. 55: 1607-162.

Barbagallo RP, Oxborough K, Pallett KE, Baker NR (2003) Rapid, noinvasive scrrening for perturbations of metabolism and plant growth using chlorophyll fluorescence imaging. Plant Physiol. 132: 485-493.

Cassana, FF, Braga, EJB, Bacarin, MA, Falqueto, AR, Peters, JA (2008) Atividade fotoquímica máxima do fotossistema II em plantas de batata-doce cultivadas in vitro e aclimatizadas. Rev. Bras. Agrociência 14 (in press)

Fabbri A, Sutter E, Dunston SK (1986) Anatomical changes in persistent leaves of tissue cultured strawberry plants after removal from culture. Sci. Hort. 28: 331-374.
Fuentes G, Talavera C, Desjardins Y, Santamaria JM (2005) High irradiance can minimize the negative effect of exogenous sucrose on the photosynthetic capacity of in vitro grown coconut plantlets. Biol. Plant. 49: 7-15.

Guo YP, Guo DP, Zhou HF, Hu MJ, Shen YG (2006) Photoinhibition and xanthophylls cycle activity in bayberry (Myrica rubra) leaves induced by high irradiance. Photosynthetica 44: 439-446.

Le VQ, Samson G, Desjardins Y (2001) Opposite effects of exogenous sucrose on growth, photosynthesis and carbon metabolism of in vitro plantlets of tomato (L. esculentum Mill.) grown under two levels of irradiances and $\mathrm{CO}_{2}$ concentration. J. Plant Physiol. 158: 599-605.

Murashige T, Skoog F (1962) A revised medium for rapid growth and bioassay with tobacco tissue culture. Physiol. Plant. 15: 473-497.

Semorádová S, Synková H, Pospíśilová J (2002) Responses of tobacco plantets to change of irradiance during transfer from in vitro to ex vitro conditions. Photosynthetica 40: 605-614.

Viña GLD, Alfaro FP, Driscoll SP, Mitchell VJ, Parry MA, Lawlor DW (1999) Effects of $\mathrm{CO}_{2}$ and sugars on photosynthesis and composition of avocado leaves grown in vitro. Plant Physiol. Biochem. 37: 587-595.

Zonta EP, Machado, AA (1987) SANEST - Statistical Analysis System for Microcomputers. Pelotas: DMEC/IFM/UFPel 